\title{
FEATURES OF QUALITY MANAGEMENT IN HEALTHCARE OF THE REPUBLIC OF KAZAKHSTAN
}

\author{
Nursulu Alashbaieva ${ }^{1, *}$, Kulyash Baigabulova ${ }^{2}$, Nazgul Syrlybayeva $^{3}$ \\ ${ }^{1}$ Kazakh University of Economics Finance and international trade, Nur-Sultan, ul.Ahmet Zhubanova, \\ 7020000, Nur-Sultan, Kazakhstan \\ ${ }^{2}$ Eurasian national University L.N. Gumilyova, ul. Satpaeva, 2, 010008, g. Nur-Sultan, Kazakhstan, \\ ${ }^{3}$ Al-Farabi Kazakh National University, Al-Farabi Ave., 71, 050040 Almaty, Kazakhstan
}

\begin{abstract}
The main factor that determined the relevance of the author's research is the need to continue and develop the processes of modernization in the healthcare economy, provided for in the framework of the state program of health development of the Republic of Kazakhstan "Densaulyk", as well as the "Strategy-2050. The article shows the significant changes affecting the increase in the provision of medical organizations with high-tech medical and diagnostic equipment, as well as the solution of issues related to their informatization through the introduction of medical information and analytical systems aimed at automating the main processes of medical activity. The authors prove that in order to achieve the highest efficiency and effectiveness of the functioning of medical organizations, it seems appropriate to introduce process-oriented quality management systems in healthcare, which are a synthesis of professional management and modern information technologies.

The objectives of the study in the study of the main aspects of quality management in healthcare organizations and the analysis of the quality management system are defined. On the basis of the study, the authors draw the appropriate conclusions.
\end{abstract}

\section{Introduction}

President Nazarbayev N.A. In his Address to the people of Kazakhstan, "New Kazakhstan in a New World" emphasized that one of the directions of state policy at a new stage in the development of our country should be the improvement of the quality of medical services and the development of a high-tech healthcare system. Improving the management of the quality of medical services occupies an important place in the context of the strategic development of healthcare in Kazakhstan until 2020. Recognizing the importance of the reasons voiced by the President, today we are actively promoting the entry of the healthcare system of the Republic of Kazakhstan into the stage of active institutional transformations,

*Corresponding author: shynar.turarova@gmail.com 
the development of human resources at all levels of the industry and the provision of hightech medical care, the purpose of which is to improve the efficiency, accessibility and effectiveness of the medical care system that provides improvement health status of the population.

Under the term "quality", we consider the degree of conformity of a product or service with the expectations of the consumer. Quality has always been an important basis for competition between companies, but recent research in this area allows us to use quality as one of the main characteristics of the process, thereby adding another lever of control. Indeed, by defining the required level of quality (zero defects, 6 sigma), you can monitor and manage changes in the process. Within the approach, there are many different methodologies suitable for completely different companies. As in the case of knowledge management, the company should built and develop with the chosen approach to quality management.

\section{Literature review}

Scientific bases of healthcare economy formation are necessary for development of the quality of medical care assessment procedures, and also for activity efficiency of the medical organizations, the following works are devoted: Abramov A. Y. [1], Agalakov V. I. [2], Adzhiev M. E. [3], Arshinova, N. A. [4], Bykova Z. E. [6], Emanuel Y. V., Khotin A. J [7], Yamshchikov A., Tkach O., Ardasova O. [8], etc. Theoretical and applied aspects of processoriented control are investigated in the works of Aristova O. V. [9], Bely E. [10], Valentinova N. I. [11], Kane M. M. [12] and others.

As well as Kazakh scientists studied the issues of quality management: Bokenova G. K. [5], Soloviev V. I. [13], Rakhisheva A. B. [14] and others.

\section{Main part}

Head of state Nursultan Nazarbayev in his missive to the people of Kazakhstan dated by December 14, 2012 "Strategy" Kazakhstan-2050": The new political course of the established state "in order to become one of the 30 most developed countries in the world by 2050 , it is necessary to overcome the development gap among the countries of the Organization for economic cooperation and development. In the field of health is the gradual introduction of standards of OECD countries aimed at improving the quality and accessibility of health services, improving the efficiency of management and financing of the health system. During the implementation of previous state programs, the potential of the health care system of Kazakhstan was strengthened, elements of market mechanisms were introduced and modern medical technologies were transferred.

The decree of the President of the Republic of Kazakhstan dated by January 15, 2016 approved the State program of health development of the Republic of Kazakhstan "Densaulyk" for 2016-2019 [16]. The new Program is aimed at consolidating and developing the results achieved and solving problems in health protection in accordance with new challenges, and will also become the basis for the planned development of the industry until 2050. In modern conditions of functioning of the Kazakhstan healthcare institutions is a problem of creation and introduction of new forms of governance that ensure maximum efficiency at minimum cost and high quality services. The means of achieving the established level of quality of products and services, as well as improving the efficiency of activities is the quality management system (hereinafter - QMS), which meets the requirements of international standards ISO 9000 series, developed by the international organization for standardization.

The principles of ISO international standards can be applied in the creation of QMS in any industry, including in health care, because the principle of satisfaction of consumer 
requirements laid down in the basis of the standard is at the same time the main goal of any health care institution [16]. The use of these standards in medical institutions can significantly improve the efficiency of management in both basic (provision of medical services) and auxiliary processes (management of resources, including personnel, strategic and tactical management; manage improvement processes, identify and eliminate problem areas and risks, etc.). ISO standards are based on quality assurance methods, i.e. achieving high performance indicators, are comprehensive and cover all activities of the institution [17]

The management principles laid down in the ISO standards are universal: leadership of management, process approach, customer orientation, staff involvement, systematic approach to management, fact-based decision-making, partnerships with suppliers and continuous improvement. The application of these principles gives the management of the institution tools for effective management.

9000 series standards define some General principles in the policy of the laboratory management in the field of quality, allowing to choose some management models directly related to its specialization. The quality system-from the use of the recommendations of the standards, benefits by using the already tested solutions to increase the economic effect.

The 9000 series standards use three models of product quality assurance, which makes it possible to make an informed decision on application and implementation.

The ISO 9001 quality system belongs to the first of the three models and reflects the possibilities of application at the development stages. The second model includes the ISO 9002 standard concerning quality systems at the production and installation stages. The third model is ISO 9003 on quality systems at the control and testing stages. The standard for the first model reflects almost all the requirements for quality management, the second model allows some relaxation in quality management, the third model contains only the most important elements of quality management.

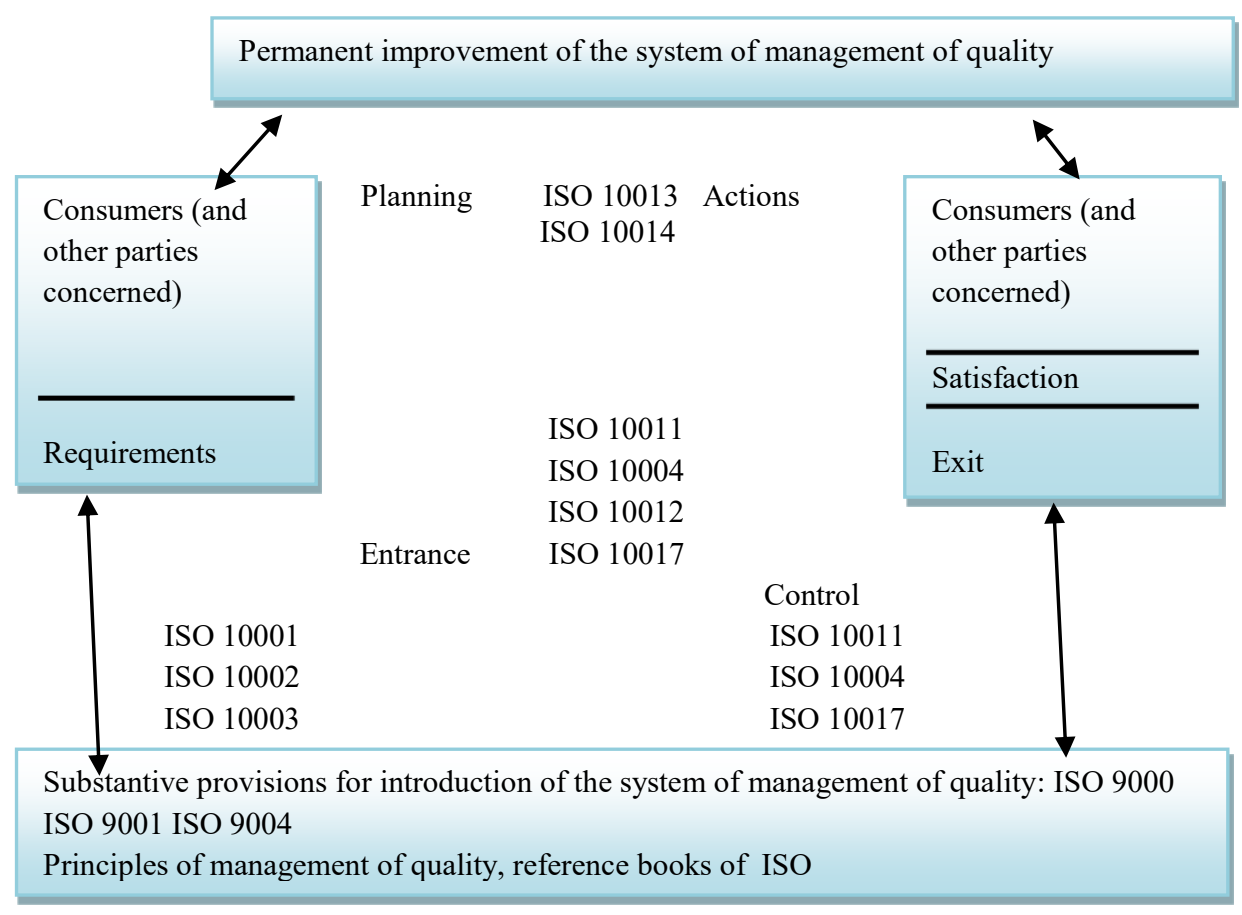

Fig 1. Application of quality management system. 
Standards developers try to create as many similar names as possible in standards, but the desire to generalize everything can prevent the introduction of new ideas into standards.

ISO 9000 series standards helps to create a management system in which all functions and methods are formatted and documented (figure 1).

There are two types of processes in the 9000 series standards, the first is the documentation of the quality assurance processes themselves, the second class is the documentation of the validation of the quality assurance processes.

The world health organization (WHO) has developed standards for some individual programs and areas.

Standardization is recognized as a key component in the management of the national laboratory network with limited resources, thus allowing economical use of resources, while maintaining the quality of services [18].

The need to create national programs, training, support laboratories to improve quality, the introduction of standards, integrated quality systems and preparation for accreditation of laboratories are the basis for the reform of laboratory diagnostics.

In modern medicine, effective diagnosis, prevention and treatment are impossible without the use of clinical laboratory studies. It is believed that up to $70-80 \%$ of the information relevant for the diagnostic process is provided by clinical laboratory studies $[3,6]$.

Of particular importance is the question of compliance of laboratory results with the purpose of use-the solution of clinical problems (diagnostic issues solved by a doctor) and their analytical reliability [18].

The actual issue is the quality of laboratory examination, which is aimed at reducing the risk for patients and providing diagnostic information to clinicians.

The developed quality management system applies to all activities of health care enterprises.

The developed QMS is based on the requirements of ISO 9001:2009. The documentary basis for the regulation of medical laboratories is a modern understanding of the ways to achieve, maintain and continuously improve the quality of medical laboratories, which are set out in the international standard ISO 15189: 2012 " Medical laboratories. Requirements for quality and competence". The standard was developed by the Technical Committee for standardization TC 212 of the International organization for standardization "Clinical laboratory studies and systems for in vitro diagnostics".

As part of the issue of improving the quality of medical services, attention should be focused on the problem of quality control of medical care in the Republic of Kazakhstan. Currently, control is carried out mainly through inspections-identifying errors, correcting them and recovering damages from responsible employees.

When implementing proposals to optimize the management system in medical organizations based on a process-oriented approach, it is necessary, as a first stage, to consider the main types of organizational structures of health care organizations of Kazakhstan, as well as to identify their possible limitations and main features.

The advantages of the process-oriented management system over other systems used in the majority of Kazakhstan medical organizations are that they allow to increase the speed of service to consumers of medical services, minimize the impact of the human factor, reduce costs, increase productivity and improve the quality of medical services.

The process-oriented approach is based on the concept of process. The process is any operating or administrative system that converts resources into desired results.

The ISO 9001:2009 international quality standards define a process as an activity that uses resources and is managed to convert inputs into outputs [19]. In this case, the output of one process often forms the input of the next, and the processes themselves are numerous and interrelated.

A number of provisions has a particular value for solving the problem of forming a system 
of process-oriented quality management of medical services:

- the personnel service at the enterprise should carefully carry out the selection of employees and strive to keep only those who are really able to work effectively;

- providing employees in addition to physical (in the form of wages) and emotional attachment to the organization through the formation of their vision of the goals of the organization and ways to achieve them, understanding their role and importance in this process;

- to improve the efficiency of medical services, it is necessary that the employee has mastered the relevant knowledge and skills in order to perform their functional duties in the best possible way;

- formation of team spirit among employees of the organization, which becomes relevant in medical organizations due to the fact that their activities are associated with emotional stress caused by various stressful factors;

- empowering employees, which is very important for the contact personnel (frontline) of the medical organization, for whom the ability to make independent decisions in difficult situations when working with clients can become one of the means of improving the quality of service;

- the introduction of a quality of service evaluation system, including incentives and rewards for the success of employees, which would help to improve the efficiency of their work;

- positioning the employee as the main client of the company, which implies regular monitoring of the degree of satisfaction of employees and their needs.

For the successful functioning of the quality management system, activities and their interrelationships must be clearly defined. Often the output of one process forms directly the input of the next. Application in the organization of the system of processes along with their identification and interaction, as well as process management can be considered a "process approach". When describing processes and their interaction in QMS, the Deming - Shuhart PDCA cycle is effectively used in combination with quality tools. The advantage of the process approach is the possibility of control, which is provided at the junction of individual processes, as well as their combination and interaction.

The quality management system should integrate all processes to implement the quality policy, objectives and meet the needs and requirements of consumers.

\section{Conclusion}

Thus, process-oriented quality management of medical services in this study should be understood as a method of management of medical organizations, based on the modeling of business processes of their activities on the basis of medical information and analytical systems, the main result of the implementation is to improve the quality and availability of medical services.

Medical laboratory services are essential for patient care and therefore should meet the needs of patients and clinical staff responsible for patient care. Where national, regional and local regulations are applicable, it is recommended that medical laboratory services include examination of patients in consultation and that laboratories actively participate not only in the diagnosis and treatment of patients, but also in the prevention of diseases.

In order to improve the efficiency of the quality management system of medical services, it is necessary to use a process-oriented approach. Its main advantages are the formation of employees 'focus on the final result, as well as the delegation of authority and responsibility to the" owners " of the processes, thereby increasing the efficiency of management. In addition, the construction of a process-oriented management system in health care institutions helps to increase the speed of service to consumers of medical services, minimize 
the human factor, reduce costs and increase productivity, as well as improve the quality of medical services through the use of automated information and analytical systems.

\section{References}

1. Abramov A. Y. International accreditation standards for healthcare organizations - M.: 2013. $-222 \mathrm{p}$

2. Agalakov V. I. Quality of medical care. Vyatka medical Bulletin. 2, 47-56, 2003

3. Adzhiev M. E. Basic problems of quality management system of medical organization / / Young scientist. 2013. - No. 12. 561-562 p.

4. Arshinova, N. A. Organization of quality management system of medical care in the regional clinical hospital / / quality Management in health care. -2014. - No. 1. -20-25 p.

5. Bokenova, G. K. Evolution of the quality system. International organization for quality system ISO //Bulletin of KASU. - 2005-No. 4. 71 p.

6 . Bykova Zh. E. The use of the methodology of score assessment of medical services as a stabilizing factor of health care costs. - 2000. - No. 5. 12-15 p.

7. Emanuel Yu. V., Khotin A. JL Application of quality management system in healthcare organizations. // Clinical and laboratory consultation. - 2013. - No. 2. 4-12 p.

8. Coachmen A., Tkach O., Ardasheva On, the Introduction of quality indicators of public services for the provision of medical care. // Social policy and social partnership. - 2014. No. 7. 67-71 p.

9. Aristov O. V. quality Management: textbook / O. V. Aristov. - Moscow: Infra-M, 2014. $240 \mathrm{p}$.

10. E. Competitiveness and product quality: two levels of management / / Marketing. - 2015. - No. 4. 29-34 p.

11. Valentinova N. I. quality Management: textbook-M.-2010. 242 p.

12. Kane M. M. Systems, methods and tools of quality management: textbook-St. Petersburg.: Peter. 2016. 348 p.

13. Soloviev V. I. Productive relationships in the team as a factor of quality management. Bulletin of the Kazakh University of Economics, Finance and international trade. No. 1. 2018. 3-7 p.

14. Rakisheva A. B. Modern content management in the enterprise. Bulletin Of The University "Turan". No. 1 (77). 2018. 21-27 p.

15. Civil code of the Republic of Kazakhstan. http://www.kstu.kz/wpcontent/uploads/2018/11/grazhdanskij-kodeks.pdf (accessed 20.11.2019.)

16.Law of the Republic of Kazakhstan "on health care system" https://online.zakon.kz/document/?doc_id=1040053 (accessed 20.11.2019)

17.Message of the President of Kazakhstan N. Nazarbayev to the people of Kazakhstan dated 31.01.2017 "the Third modernization of Kazakhstan: global competitiveness". http://wap.akorda.kz/

18. Emanuel Y. V., Khotin A. JL, Application of quality management system in healthcare organizations. // Clinical and laboratory consultation. - 2013. - No. 2. 4-12 p.

19. Harrington D. Perfection of change management: a textbook / D. Harrington. - Moscow: RIA "Standards and quality". 2013. 290 p. 